\title{
Expert endoscopists with high adenoma detection rates frequently detect diminutive adenomas in proximal colon
}

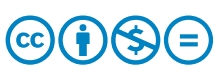

\author{
Authors \\ Hata $^{1,5}$, Hidenobu Watanabe ${ }^{6}$, Yosuke Tsuji $^{2}$, Kazuhiko Koike ${ }^{2}$ \\ Institutions \\ 1 Gastroenterology, Toyoshima Endoscopy Clinic, Tokyo, \\ Japan \\ 2 Department of Gastroenterology, Graduate School of \\ Medicine, The University of Tokyo, Tokoyo, Japan \\ 3 Department of Gastroenterology and Hepatology, \\ International University of Health and Welfare, Mita \\ Hospital, Tokyo, Japan \\ 4 Department of Gastroenterology, Sanraku Hospital, \\ Chiyoda-ku, Japan \\ 5 Department of Surgical Oncology, Graduate School of \\ Medicine, The University of Tokyo, Japan \\ 6 Pathology and Cytology Laboratory Japan, Tokyo, Japan
}

Osamu Toyoshima ${ }^{1,2}$, Toshihiro Nishizawa ${ }^{1,3}$, Shuntaro Yoshida ${ }^{1,2}$, Kazuma Sekiba ${ }^{1,2}$, Yosuke Kataoka ${ }^{1,4}$, Keisuke

submitted 30.12 .2019

accepted after revision $\quad 2.3 .2020$

\section{Bibliography}

DOI https://doi.org/10.1055/a-1136-9971 |

Endoscopy International Open 2020; 08: E775-E782

(c) Georg Thieme Verlag KG Stuttgart · New York

elSSN 2196-9736

Corresponding author

Osamu Toyoshima, MD, Director, Gastroenterology,

Toyoshima Endoscopy Clinic, 6-17-5 Seijo, Setagaya-ku,

Tokyo 157-0066, Japan

Fax: +81-3-5429-9511

t@ichou.com

\section{ABSTRACT}

Background and study aims Adenoma detection rate (ADR) is an important quality indicator in colonoscopy, and improved ADR decreases the incidence of colorectal cancer. We investigated differences in polyp detection according to the endoscopist's ADR.

Patients and methods We performed a propensity-score matching study using baseline patient characteristics of age, sex, body mass index, family history of colorectal cancer, smoking, drinking, indication for colonoscopy, bowel preparation, and colonoscope type. We compared polyp detection and colonoscopy procedures between patients who underwent colonoscopy by high-ADR endoscopists (high ADR group) and by low-ADR endoscopists (low ADR group).

Results We matched 334 patients in the high ADR group with 334 in the low ADR group. The ADR was $44.0 \%$ and $26.9 \%$ for the high-ADR and low-ADR endoscopists, respectively. Proximal, nonprotruding, and diminutive adenomas were more frequently detected by high-ADR endoscopists than by low-ADR endoscopists (all $P<0.001$ ); similarly, more high-risk adenomas were detected by high-ADR endoscopists $(P=0.028)$. Furthermore, more sessile serrated polyps detected by high-ADR endoscopists $(P=0.041)$. High-ADR endoscopists more frequently performed pancolonic chromoendoscopy $(P<0.001)$.

Conclusions Expert detectors often found nonprotruding and diminutive adenomas in the proximal colon along with increased detection rate of high-risk adenomas. Low-ADR endoscopists need to recognize the features of missed adenomas to improve their ADRs.

\section{Introduction}

Colorectal cancer (CRC) is the third most commonly diagnosed cancer (1.8 million cases, $10.2 \%$ of the total cancers). CRC is responsible for the second largest number of deaths $(881,000$ deaths, 9.2\%) [1]. Colonoscopy has been associated with a reduced incidence of CRC. Screening colonoscopy has been associated with reduced CRC mortality [2]. Screening for CRC has resulted in a significant reduction in CRC incidence through the detection and removal of adenomatous polyps and other precancerous lesions, and incidence reduction and early detection of CRC has in turn resulted in a reduction in CRC mortality [3]. The adenoma detection rate (ADR) is an important quality indicator of colonoscopy and is inversely associated with the risks of interval CRC, advanced-stage interval cancer, and fatal interval cancer [4,5]. Increased ADR has been reported to be associated with a reduced risk of interval CRC and death [6]. Therefore, it is essential to know the type of adenomas that 
are missed by endoscopists with low ADR. However, it remains unclear.

We investigated the differences in detected polyps and colonoscopy procedures between patients who underwent colonoscopy by endoscopists with either a high or low ADR.

\section{Patients and methods}

\section{Ethics}

This retrospective study was approved by the Ethical Review Committee of the Hattori Clinic on September 6, 2019 (approval no.S1909-U06). Written informed consent was obtained from the participants. All clinical investigations were conducted according to the ethical guidelines of the Declaration of Helsinki.

\section{Study population}

This propensity-score matching study comprised subjects who agreed to participate in the study and underwent colonoscopy by board-certificated endoscopists at the Toyoshima Endoscopy Clinic, an outpatient clinic specializing in endoscopy, between April and November 2017. Colonoscopy was performed to evaluate symptoms (i. e., bleeding including positive results of fecal occult blood test, abdominal symptoms, and abnormal bowel habits), for screening, or for polyp surveillance. We excluded patients who were not willing to undergo removal of colorectal polyps, patients who had previously been diagnosed with CRC and/or inflammatory bowel disease, and/or had undergone colorectal surgery except appendectomy, and patients who had indications for treatment including colorectal polypectomy and hemostasis. We excluded colonoscopy procedures that did not reach the cecum due to bowel stenosis, procedures with poor bowel preparation precluding complete observation, and procedures that did not remove all the polyps due to the large size and/or number of polyps [7-9]. We removed polyps numbering 10 or less, those with a diameter of $15 \mathrm{~mm}$ or less, and those with a cumulative diameter of $30 \mathrm{~mm}$ or less, at a single colonoscopy procedure. Details on baseline characteristics, polyp detection, and colonoscopy procedures were obtained through review of patient medical records.

\section{Diagnosis of polyps}

To endoscopically diagnose colorectal polyps, we used the updated Paris Endoscopic Classification of superficial neoplastic lesions in the digestive tract [10]. We primarily diagnosed a polyp as a sessile serrated polyp (SSP) according to the following findings: proximal location; flat, elevated, or sessile; irregular shape; indistinctive border; cloud-like surface; mucus cap; normal or pale color; none or dilated vessels, and/or dilated crypts [11]. Polyp size was measured by placing a closed snare or forceps, which has a thickness of $2 \mathrm{~mm}$, against the lesion. Lesions diagnosed as adenomas or SSPs were removed either by hot or cold polypectomy using a snare or forceps or by endoscopic mucosal resection on the examination day.

All resected specimens were examined histologically under hematoxylin and eosin staining. One experienced gastrointestinal pathologist (H.W.) diagnosed the polyps, including adeno- mas and SSPs, according to the World Health Organization criteria [12]. Traditional serrated adenomas were included in the adenoma category, but SSPs were not. An advanced adenoma was defined as an adenoma with a villous component, with a size larger than $10 \mathrm{~mm}$, or with high-grade dysplasia based on the World Health Organization definition [12]. Low-risk adenomas were defined as one or two tubular adenomas less than 10 $\mathrm{mm}$ and high-risk adenomas were defined as at least one advanced adenoma or three or more adenomas [13]. Only lesions that were histologically confirmed as adenomas or SSPs were counted [14].

\section{Colonoscopy equipment}

Patients underwent colonoscopy with an Elite CF290 endoscopy system (CV-290 and CLV-290, Olympus, Japan) with a 290 series colonoscope (CF-HQ290Z, CF-HQ290, or PCFH290Z, Olympus, Japan) or a 260 series colonoscope (PCFPQ260 or $\mathrm{CF}-\mathrm{H} 260)$ and a carbon dioxide $\left(\mathrm{CO}_{2}\right)$ insufflator (UCR $\mathrm{CO}_{2}$ regulation unit, Olympus, Japan). NBI was available for all the scopes. A flushing pump (OFP-2, Olympus, Japan) was used for the 290 series colonoscope. PCF-H290Z and PCFPQ260 were used for patients aged 80 years or older, patients aged 70 years or older who had undergone a previous abdominal surgery, and patients likely to experience a difficult insertion due to a colon adhesion found during a previous colonoscopy [9]. We used an image filing system (T-File System; STS Medic, Japan).

\section{Colonoscopy procedure}

Small shaking, jiggling, and right turn shortening maneuvers have been frequently used for colonoscope insertion [9]. Extra gas and liquid were aspirated and removed as much as possible. For colonic insufflation, $\mathrm{CO}_{2}$ was administered through the UCR for patients without chronic respiratory failure. Colonoscopies were performed under conscious sedation with midazolam $(0.5$ to $10 \mathrm{mg})$ and/or pethidine hydrochloride $(17.5$ to $70 \mathrm{mg})$ according to the patient's willingness. In the absence of contraindications, we administered 10 to $20 \mathrm{mg}$ of scopolamine butylbromide or 0.5 to $1 \mathrm{mg}$ glucagon (genetic recombinant).

The observation time for withdrawal of the colonoscope was standardized as at least 6 minutes [15]. Pancolonic chromoendoscopy (PCC) was performed at the discretion of each endoscopist. PCC involved pancolonic spraying with $0.05 \%$ indigo carmine using a $20-\mathrm{mL}$ syringe placed directly through the colonoscope accessory channel. We repeated the administration of $5 \mathrm{~mL}$ indigo carmine with $10 \mathrm{~mL}$ air-spraying 10 to 20 times during the withdrawal procedure, and the pools of excess dye were suctioned before the examination. The colonoscope was sequentially withdrawn as the prescribed position changed $[16,17]$ : the ascending colon/hepatic flexure was examined in the left lateral decubitus position; the transverse colon was examined in the supine position; the splenic flexure, descending colon, and sigmoid-descending colon junction were examined in the right lateral position; and the sigmoid colon and rectum were examined in the right lateral position.

Patients involved in this study underwent colonic preparation with $2 \mathrm{~L}$ of polyethylene glycol solution administered orally 
- Table 1 Baseline characteristics of patients before and after propensity-score matching.

\begin{tabular}{|c|c|c|c|c|c|}
\hline & \multicolumn{2}{|l|}{ Before matching } & \multicolumn{3}{|l|}{ After matching } \\
\hline & Low-ADR group & High-ADR group & Low-ADR group & High-ADR group & $P$ value \\
\hline No. of patients & 418 & 599 & 334 & 334 & \\
\hline Age $^{1}$, years & $49.9(11.6)$ & $53.8(13.2)$ & $50.2(11.9)$ & $50.1(12.1)$ & 0.91 \\
\hline Sex, female & 213 & 334 & 171 & 170 & 0.94 \\
\hline Body mass index ${ }^{1}, \mathrm{~kg} / \mathrm{m}^{2}$ & $22.1(3.0)$ & $22(3.1)$ & $22.1(2.9)$ & $22.0(3.0)$ & 0.82 \\
\hline Past malignancy except CRC, \% & 7.9 & 7.9 & 7.8 & 6.6 & 0.55 \\
\hline Family history of CRC, \% & 14.6 & 14.5 & 14.1 & 13.5 & 0.82 \\
\hline Smoking, \% & 11.7 & 9.7 & 10.8 & 10.2 & 0.80 \\
\hline Drinking, \% & 28.0 & 22.7 & 25.7 & 24.3 & 0.66 \\
\hline \multicolumn{6}{|l|}{ Indication for colonoscopy } \\
\hline - Evaluation of symptoms & 109 & 145 & 85 & 87 & \\
\hline - Screening & 174 & 309 & 152 & 152 & 0.90 \\
\hline - Polyp surveillance & 135 & 145 & 97 & 95 & 0.83 \\
\hline \multicolumn{6}{|l|}{ Bowel preparation grade ${ }^{2}$} \\
\hline - A & 244 & 278 & 181 & 176 & \\
\hline$\cdot \mathrm{B}$ & 146 & 241 & 125 & 132 & 0.61 \\
\hline$\cdot C$ & 28 & 80 & 28 & 26 & 0.87 \\
\hline \multicolumn{6}{|l|}{ Colonoscope type } \\
\hline - 260 series & 110 & 25 & 26 & 24 & \\
\hline - 290 series & 308 & 574 & 308 & 310 & 0.77 \\
\hline \multicolumn{6}{|c|}{$\begin{array}{l}\text { The caliper width was set to } 0.946 \text { (one standard deviation of logarithm odds for the patients who underwent colonoscopy by low-ADR endoscopists). P values were } \\
\text { calculated by the Wald test using logistic regression. } \\
\text { ADR, adenoma detection rate; CRC, colorectal cancer. } \\
{ }^{1} \text { Mean (standard deviation). } \\
{ }^{2} \text { Bowel preparation: A, all colon segments empty and clean or minor amount of fluid in the gut, but easily removed by suction; B, at least one colon segment with } \\
\text { residual amounts of brown liquid or semi-solid stool that could be easily removed or displaced; C, at least one colon segment with only partially removable stool } \\
\text { preventing complete visualization of mucosa. }\end{array}$} \\
\hline
\end{tabular}

5 hours before the procedure. Polyethylene glycol solution or magnesium citrate was added when the stool was not in the clear liquid form. The quality of bowel preparation was graded as A (all colon segments empty and clean or minor amount of fluid in the gut that was easily removed by suction), B (at least one colon segment with residual amounts of brown liquid or semi-solid stool that could be easily removed or displaced), C (at least one colon segment with only partially removable stool preventing complete visualization of mucosa), or D (at least one colon segment that could not be examined due to the presence of remaining solid stool). The following colon segments were rated: rectum, sigmoid colon, descending colon, transverse colon, and ascending colon/cecum [18]. Patients identified with grade D bowel preparation during the colonoscopy were excluded.

\section{Statistical analysis}

We calculated average ADR of all enrolled procedures and ADRs for each endoscopist, during the study period. An endoscopist having an ADR higher than the average ADR was defined as a high-ADR endoscopist, and an endoscopist having an ADR lower than the average ADR was defined as a low-ADR endoscopist [19-21]. We divided the patients into those underwent colonoscopy by a high-ADR endoscopist (the high-ADR group) and those who underwent colonoscopy by a low-ADR endoscopist (the low-ADR group).

Baseline patient characteristics were age, sex, body mass index, past malignancy except $C R C$, first-degree relative with a history of CRC, smoking (Brinkman score $\geq 400)$, drinking $(\geq 1$ cup of alcohol per day), indication for colonoscopy (evaluation of symptoms, screening, or polyp surveillance), bowel preparation grade (A, B, or C), and the type of colonoscope (290 series or 260 series). These characteristics were clinically important 


\section{$N=1147$}

1 without willingness to remove polyps

65 with previous colorectal cancer or inflammatory bowel disease

22 with indication for treatment

3 with incomplete cecal intubation due to colon stenosis

5 with poor bowel preparation

32 with incomplete removal of all polyps due to large size of polyps

2 with incomplete removal of all polyps due to large number of polyps

$N=1017$ (mean ADR: $37.0 \%$ )

Patients underwent colonoscopy by low-ADR endoscopists $\mathrm{N}=418$ (mean ADR: $26.1 \%$ )
Patients underwent colonoscopy by high-ADR endoscopists $\mathrm{N}=599$ (mean ADR: $44.6 \%$ )

Propensity-score matching

$N=334$ (mean ADR: $26.9 \%$ )

$N=334$ (mean ADR: $44.0 \%$ )

- Fig. 1 Flowchart of patient enrollment and propensity-score matching. ADR, adenoma detection rate.

and reported to be associated with colon polyp detection [7, 9, $15,18,22-26]$.

To reduce the effects of selection bias and potential confounding factors in this study, we performed rigorous adjustments for significant differences in all the baseline characteristics of patients by using propensity-score matching $[27,28]$. Patients who underwent colonoscopy by high-ADR endoscopists were identified and propensity-score matched with those who underwent colonoscopy by low-ADR endoscopists. Matching was performed with a 1:1 matching protocol using nearest-neighbor matching without replacement and with a caliper width of 0.946 , which was one standard deviation of logarithm odds for patients who underwent colonoscopy by lowADR endoscopists ( $>$ Table 1) [29-31].

Following the propensity-score matching, we compared the polyp detection rates, numbers of polyps per procedure, and the colonoscopy procedures between the two groups. The polyp detection rates included ADRs, advanced ADRs, low-risk ADRs, high-risk ADRs, SSP detection rates, and adenoma plus SSP detection rates. The numbers of polyps included the total number of adenomas, number of adenomas by location, number of adenomas by morphology, number of adenomas by size, number of SSPs, and number of adenomas plus SSPs. The colonoscopy procedures included insertion time, withdrawal time including the time required for polypectomy, and whether PCC was performed. We assessed $P$ values by using the Wald test with logistic regression.

Statistical significance was considered a two-sided $P<0.05$. All statistical analyses were performed using $R$ version 3.5.1( $R$ Core Team 2018, R Foundation for Statistical Computing, Vienna, Austria)

\section{Results}

\section{Study population}

We identified 1017 individuals who met our inclusion criteria ( Fig. 1). These patients underwent colonoscopy by 13 endoscopists. The average ADR of the endoscopists during this period was $37.0 \%$. We defined 11 physicians as low-ADR (26.1\%, range $18.2 \%-35.1 \%$ ) endoscopists and two physicians as high-ADR (44.6\%, range $37.6 \%-45.3 \%$ ) endoscopists. Of the 1017 patients, we divided 418 into low-ADR group and 599 into highADR group. Prior to propensity-score matching, there were differences between the two groups in the baseline patient characteristics of age, bowel preparation, and the colonoscope used ( $\triangleright$ Table 1). Using propensity-score matching, 334 patients in the high-ADR group were matched with 334 patients in the low-ADR group. After matching, there was no longer any significant difference between the two groups with respect to any of the baseline characteristics.

\section{Outcomes for the matched patients}

A comparison of outcomes between the matched patients in the low-ADR group and the high-ADR group is shown in $>$ Table 2. The ADR was $44.0 \%$ and $26.9 \%$ for the high-ADR and lowADR endoscopists, respectively. The number of adenomas detected in the high-ADR group was higher than that in the lower-ADR group. The number of adenomas per positive procedure of the high-ADR group was higher than that of the low-ADR group. The number of adenomas identified in the proximal colon, type 0 -II adenomas, and adenomas $\leq 5 \mathrm{~mm}$ was larger in 
Table 2 Comparison of outcomes in patients who underwent colonoscopy by low-ADR endoscopists and patients who underwent colonoscopy by high-ADR endoscopists after propensity-score matching.

\begin{tabular}{|c|c|c|c|}
\hline & Low-ADR group & High-ADR group & $P$ value \\
\hline & $\mathbf{N}=334$ & $N=334$ & \\
\hline Adenoma detection rate $(95 \% \mathrm{Cl})$ & $26.9 \%(22.2-31.7)$ & $44.0 \%(38.7-49.3)$ & $<0.001$ \\
\hline No. of adenomas ${ }^{1}$ & $0.374(0.719)$ & $0.751(1.069)$ & $<0.001$ \\
\hline No. of adenomas ${ }^{2}$ & $1.389(0.714)$ & $1.707(1.069)$ & 0.0080 \\
\hline \multicolumn{4}{|l|}{ No. of adenomas by location ${ }^{1}$} \\
\hline - Proximal colon & $0.180(0.456)$ & $0.533(0.902)$ & $<0.001$ \\
\hline - Cecum & $0.033(0.179)$ & $0.078(0.290)$ & 0.016 \\
\hline - Ascending colon & $0.087(0.303)$ & $0.204(0.537)$ & $<0.001$ \\
\hline - Transverse colon & $0.060(0.250)$ & $0.251(0.567)$ & $<0.001$ \\
\hline - Distal colon & $0.156(0.424)$ & $0.192(0.501)$ & 0.32 \\
\hline - Descending colon & $0.045(0.221)$ & $0.030(0.171)$ & 0.33 \\
\hline - Sigmoid colon & $0.111(0.333)$ & $0.162(0.456)$ & 0.10 \\
\hline - Rectum & $0.039(0.194)$ & $0.027(0.162)$ & 0.39 \\
\hline - Rs & $0.027(0.162)$ & $0.012(0.109)$ & 0.16 \\
\hline - Ra & $0.006(0.077)$ & $0.003(0.055)$ & 0.56 \\
\hline$-R b$ & $0.006(0.077)$ & $0.012(0.109)$ & 0.41 \\
\hline \multicolumn{4}{|l|}{ No. of adenomas by morphology ${ }^{1}$} \\
\hline - Type 0-I & $0.087(0.322)$ & $0.081(0.314)$ & 0.81 \\
\hline - $0-1 \mathrm{p}$ & $0.006(0.077)$ & $0.003(0.055)$ & 0.56 \\
\hline-0 -Is & $0.081(0.314)$ & $0.078(0.310)$ & 0.90 \\
\hline - Type 0-II & $0.287(0.611)$ & $0.671(0.998)$ & $<0.001$ \\
\hline - 0-IIa & $0.287(0.611)$ & $0.659(0.988)$ & $<0.001$ \\
\hline$-0-\| 1 c$ & $0.000(0.000)$ & $0.012(0.109)$ & 0.045 \\
\hline \multicolumn{4}{|l|}{ No. of adenomas by size ${ }^{1}$} \\
\hline . $\leq 5 \mathrm{~mm}$ & $0.293(0.598)$ & $0.683(1.011)$ & $<0.001$ \\
\hline$-1-3 \mathrm{~mm}$ & $0.222(0.513)$ & $0.512(0.823)$ & $<0.001$ \\
\hline$-4-5 \mathrm{~mm}$ & $0.072(0.281)$ & $0.171(0.436)$ & $<0.001$ \\
\hline - $6-9 \mathrm{~mm}$ & $0.060(0.250)$ & $0.057(0.245)$ & 0.88 \\
\hline . $\geq 10 \mathrm{~mm}$ & $0.021(0.143)$ & $0.012(0.109)$ & 0.36 \\
\hline Advanced adenoma detection rate & $2.10 \%$ & $1.20 \%$ & 0.37 \\
\hline Low-risk adenoma detection rate & $23.7 \%$ & $36.8 \%$ & $<0.001$ \\
\hline High-risk adenoma detection rate & $3.29 \%$ & $7.19 \%$ & 0.028 \\
\hline SSP detection rate & $7.49 \%$ & $10.5 \%$ & 0.18 \\
\hline No. of SSPs ${ }^{1}$ & $0.081(0.284)$ & $0.141(0.453)$ & 0.041 \\
\hline Adenoma + SSP detection rate & $32.6 \%$ & $49.4 \%$ & $<0.001$ \\
\hline No. of adenomas + SSPs $^{1}$ & $0.455(0.761)$ & $0.892(1.178)$ & $<0.001$ \\
\hline
\end{tabular}


- Table2 (Continuation)

\begin{tabular}{|c|c|c|c|}
\hline & Low-ADR group & High-ADR group & $P$ value \\
\hline & $N=334$ & $N=334$ & \\
\hline \multicolumn{4}{|l|}{ Procedure } \\
\hline - Insertion time ${ }^{3}$, minutes & $5.683(2.873)$ & $4.117(2.030)$ & $<0.001$ \\
\hline - Withdrawal time ${ }^{3}$, minutes & $14.243(5.407)$ & $12.964(2.850)$ & $<0.001$ \\
\hline - Pancolonic chromoendoscopy & $88.6 \%$ & $98.2 \%$ & $<0.001$ \\
\hline \multicolumn{4}{|c|}{$\begin{array}{l}P \text { values were calculated by the Wald test using logistic regression. } \\
\text { ADR, adenoma detection rate; } \mathrm{Cl} \text {, confidence interval; SSP, sessile serrated polyp. } \\
{ }^{1} \text { Mean per procedure (standard deviation). } \\
{ }^{2} \text { Mean per positive procedure (standard deviation). } \\
{ }^{3} \text { Mean (standard deviation). }\end{array}$} \\
\hline
\end{tabular}

the high-ADR group than that in the low-ADR group (all $P<$ $0.001)$. The number of adenomas detected in the distal colon and rectum, type $0-1$ adenomas, and adenomas $\geq 6 \mathrm{~mm}$ was similar between both the groups. Advanced ADR was similar for both the groups; however, the high-risk ADR in the highADR group was higher than that in the low-ADR group $(P=$ $0.028)$. The number of SSPs in the high-ADR group was larger than that in the low-ADR group $(P=0.041)$. Insertion time and withdrawal time in the high-ADR group were shorter than that in the low-ADR group. PCC was more frequently performed in the high-ADR group than in the low-ADR group $(P<0.001)$.

\section{Discussion}

ADR is associated with the incidence and mortality of CRC, and an improvement in the ADR also reduces the incidence of CRC and its mortality [3-6]. In the present study, low-ADR endoscopists missed more proximal, nonprotruding, and/or diminutive adenomas. Some studies showed that patients who developed interval CRC are more likely to have proximal cancer than those with distal cancer $[32,33]$. There are some possible reasons for the distribution of interval CRC. One hypothesis is that some physicians may more often miss adenomas in the proximal colon than in the distal colon [34]. Lieberman et al. [13] described that failure to fully examine the proximal colon, quality of bowel preparation, variable equipment of colonoscopy, and the endoscopist's skill could lead to overlooking of the adenomas. Another possible reason is the biological differences between neoplastic lesions in the proximal and the distal colon, such as the sessile serrated lesions [35]. Interval cancers are more likely located in the proximal colon, have microsatellite instability, and have CpG island methylator phenotype. The mismatch repair defects correlated to microsatellite instability may induce a rapid accumulation of mutations and accelerated cancer development [36, 37]. Rondagh et al. [38] have reported that proximal adenomas with high-grade dysplasia/early CRC were more likely to be diminutive or nonpolypoid than the distal ones. Low-ADR endoscopists should be aware of the features of these missed adenomas and improve their ADRs.
Expert detectors more frequently diagnosed not only adenomas but also high-risk adenomas than the low-ADR endoscopists did. Guidelines for colonoscopy surveillance after screening and polypectomy issued by the United States MultiSociety Task Force on CRC recommend that patients without an adenoma undergo surveillance at 10 years, those with lowrisk adenomas undergo surveillance at 5 to 10 years, and those with high-risk adenomas undergo surveillance at 3 years [13]. If a patient undergoes colonoscopy by a low-ADR endoscopist, not only do adenomas with the potential for cancerization remain, but the surveillance interval also becomes longer, which increases the patient's chances of developing CRC. It might be better to adjust the surveillance colonoscopy interval taking into account the individual ADR of the baseline endoscopist.

In this study, advanced ADR was similar for both the groups. Greenspan et al. [39] reported that advanced ADR was variable among colonoscopists with acceptable ADRs and that colonoscopists' advanced ADRs were independent of their nonadvanced ADRs. Their results support our findings. Lee et al. [40] described that measuring total adenoma detection (mean number of adenomas per procedure and mean number of adenomas per positive procedure) as adjuncts to ADR may further enhance quality assurance. Our study revealed that the mean number of adenomas per positive procedure of the high-ADR group was significantly higher than that of the low-ADR group, and withdrawal time in the high-ADR group was shorter than that in the low-ADR group. The high-ADR endoscopists in this study efficiently detected and removed adenomas.

High-ADR endoscopists more frequently conducted PCC than the low-ADR endoscopists did. We have previously reported that PCC using the new-generation endoscopy system could detect proximal colon adenomas in addition to white-light observation and NBI observation [24]. Low-ADR endoscopists should consider applying PCC as one of the methods to raise their ADRs.

There are some possible limitations of our study. This study was a retrospective propensity-score matching comparison. Propensity-score matching might have resulted in some biases. The present study was conducted in a single center. The calculated number of colonoscopies per one endoscopist is small. 
This appears slightly suboptimal for the formal calculations of ADR and other parameters. ADR now is mainly referred for colonoscopies performed for CRC screening; however, our examination involved indication for symptom evaluation and for polyp surveillance. Patients with residual polyps that could not be removed in our clinic were excluded from the analysis. Withdrawal time included time taken for maneuvers such as polypectomy that were performed during the withdrawal phase. It was difficult to subtract polyp removal time from withdrawal time due to the retrospective study design. Interobserver variability in polyp size could have resulted in some bias. We defined an endoscopist with an ADR lower than the average ADR in this study as a low-ADR endoscopist. Consequently, the mean ADR of low-ADR endoscopists was $26.1 \%$ which was more than $25 \%$ of the recommendation for benchmark ADR [41]. In the future, investigation based on the benchmark ADR is desirable. The bowel preparation scale of this study was not a gold standard. We should have used Boston Bowel Preparation Scale or Aronchick Scale, which are international standards [42]. Studies should be planned to address these aspects and corroborate our findings.

\section{Conclusion}

In conclusion, expert detectors often found proximal, nonprotruding, and diminutive colorectal polyps and demonstrated an increased high-risk ADR.

\section{Acknowledgements}

The authors thank StaGen Co., Ltd. for statistical analyses and Editage for English editing.

\section{Competing interests}

The authors declare that they have no conflict of interest.

\section{References}

[1] Ferlay J, Colombet M, Soerjomataram I et al. Estimating the global cancer incidence and mortality in 2018: GLOBOCAN sources and methods. Int J Cancer 2019; 144: 1941-1953

[2] Wolf AMD, Fontham ETH, Church TR et al. Colorectal cancer screening for average-risk adults: 2018 guideline update from the American Cancer Society. CA Cancer J Clin 2018; 68: 250-281

[3] Nishihara R, Wu K, Lochhead P et al. Long-term colorectal-cancer incidence and mortality after lower endoscopy. N Engl J Med 2013; 369: 1095-1105

[4] Kaminski MF, Regula J, Kraszewska E et al. Quality indicators for colonoscopy and the risk of interval cancer. N Engl J Med 2010; 362: 1795-1803

[5] Corley DA, Jensen CD, Marks AR et al. Adenoma detection rate and risk of colorectal cancer and death. N Engl J Med 2014; 370: 12981306

[6] Kaminski MF, Wieszczy P, Rupinski M et al. Increased rate of adenoma detection associates with reduced risk of colorectal cancer and death. Gastroenterology 2017; 153: 98-105
[7] Kahi C], Anderson JC, Waxman I et al. High-definition chromocolonoscopy vs. high-definition white light colonoscopy for average-risk colorectal cancer screening. Am J Gastroenterol 2010; 105: 13011307

[8] Lai E], Calderwood AH, Doros G et al. The Boston bowel preparation scale: a valid and reliable instrument for colonoscopy-oriented research. Gastrointest Endosc 2009; 69: 620-625

[9] Toyoshima O, Yoshida S, Nishizawa T et al. CF290 for pancolonic chromoendoscopy improved sessile serrated polyp detection and procedure time: a propensity score-matching study. Endosc Int Open 2019; 7: E987-E993

[10] Endoscopic Classification Review Group. Update on the paris classification of superficial neoplastic lesions in the digestive tract. Endoscopy 2005; 37: 570-578

[11] Kashida H. Endoscopic diagnosis of sessile serrated polyp: A systematic review. Dig Endosc 2019; 31: 16-23

[12] Bosman FT, Carneiro F, Hruban RH et al. WHO classification of tumours of the digestive system. Fourth edition. Lyon: International Agency for Research on Cancer; 2010

[13] Lieberman DA, Rex DK, Winawer SJ et al. Guidelines for colonoscopy surveillance after screening and polypectomy: a consensus update by the US Multi-Society Task Force on Colorectal Cancer. Gastroenterology 2012; 143: 844-857

[14] Lee TJ, Rees C], Blanks RG et al. Colonoscopic factors associated with adenoma detection in a national colorectal cancer screening program. Endoscopy 2014; 46: 203-211

[15] Barclay RL, Vicari J], Doughty AS. Colonoscopic withdrawal times and adenoma detection during screening colonoscopy. N Engl J Med 2006; 355: 2533-2541

[16] East JE, Suzuki N, Arebi N et al. Position changes improve visibility during colonoscope withdrawal: a randomized, blinded, crossover trial. Gastrointest Endosc 2007; 65: 263-269

[17] Ou G, Kim E, Lakzadeh P et al. A randomized controlled trial assessing the effect of prescribed patient position changes during colonoscope withdrawal on adenoma detection. Gastrointest Endosc 2014; 80: 277-283

[18] Ell C, Fischbach W, Bronisch H] et al. Randomized trial of low-volume PEG solution versus standard PEG + electrolytes for bowel cleansing before colonoscopy. Am J Gastroenterol 2008; 103: 883-893

[19] Lee RH, Tang RS, Muthusamy VR et al. Quality of colonoscopy withdrawal technique and variability in adenoma detection rates (with videos). Gastrointest Endosc 2011; 74: 128-134

[20] Sastre LozanoVM, Moran SanchezS, Garcia Solano] et al. Relationship between the polyp detection rate and the post-colonoscopy colorectal cancer rate. Rev Esp Enferm Dig 2019; 111: 598-602

[21] Gurudu SR, Boroff ES, Crowell MD et al. Impact of feedback on adenoma detection rates: Outcomes of quality improvement program. J Gastroenterol Hepatol 2018; 33: 645-649

[22] Leung WK, Lo OS, Liu KS et al. Detection of colorectal adenoma by narrow band imaging (HQ190) vs. high-definition white light colonoscopy: a randomized controlled trial. Am J Gastroenterol 2014; 109: $855-863$

[23] Gerard DP, Foster DB, Raiser MW et al. Validation of a new bowel preparation scale for measuring colon cleansing for colonoscopy: the chicago bowel preparation scale. Clin Transl Gastroenterol 2013; 4: e43

[24] Toyoshima O, Hata K, Yoshida S et al. New-generation chromoendoscopy may increase confidence in the DISCARD2 study. Gut 2018; 67: 1742-1743

[25] Anderson JC, Butterly LF, Weiss JE et al. Providing data for serrated polyp detection rate benchmarks: an analysis of the New Hampshire Colonoscopy Registry. Gastrointest Endosc 2017; 85: 1188-1194 
[26] Hata K, Shinozaki M, Toyoshima O et al. Impact of family history of gastric cancer on colorectal neoplasias in young Japanese. Colorectal Dis 2013; 15: 42-46

[27] Rosenbaum PR, Rubin DB. The central role of the propensity score in observational studies for causal effects. Biometrika 1983; 70: 41-55

[28] D'Agostino RB Jr. Propensity score methods for bias reduction in the comparison of a treatment to a non-randomized control group. Stat Med 1998; 17: 2265-2281

[29] Normand ST, Landrum MB, Guadagnoli E et al. Validating recommendations for coronary angiography following acute myocardial infarction in the elderly: a matched analysis using propensity scores. J Clin Epidemiol 2001; 54: 387-398

[30] Austin PC. Optimal caliper widths for propensity-score matching when estimating differences in means and differences in proportions in observational studies. Pharm Stat 2011; 10: 150-161

[31] Bangalore S, Guo Y, Samadashvili Z et al. Everolimus-eluting stents or bypass surgery for multivessel coronary disease. N Engl J Med 2015; 372: 1213-1222

[32] Bressler B, Paszat LF, Chen Z et al. Rates of new or missed colorectal cancers after colonoscopy and their risk factors: a population-based analysis. Gastroenterology 2007; 132: 96-102

[33] Brenner H, Chang-Claude J, Seiler CM et al. Protection from colorectal cancer after colonoscopy: a population-based, case-control study. Ann Intern Med 2011; 154: 22-30
[34] Pohl H, Robertson D]. Colorectal cancers detected after colonoscopy frequently result from missed lesions. Clin Gastroenterol Hepatol 2010; 8: 858-864

[35] Leggett B, Whitehall V. Role of the serrated pathway in colorectal cancer pathogenesis. Gastroenterology 2010; 138: 2088-2100

[36] Arain MA, Sawhney M, Sheikh S et al. CIMP status of interval colon cancers: another piece to the puzzle. Am J Gastroenterol 2010; 105: 1189-1195

[37] Sawhney MS, Farrar WD, Gudiseva S et al. Microsatellite instability in interval colon cancers. Gastroenterology 2006; 131: 1700-1705

[38] Rondagh EJ, Bouwens MW, Riedl RG et al. Endoscopic appearance of proximal colorectal neoplasms and potential implications for colonoscopy in cancer prevention. Gastrointest Endosc 2012; 75: 12181225

[39] Greenspan M, Rajan KB, Baig A et al. Advanced adenoma detection rate is independent of nonadvanced adenoma detection rate. Am J Gastroenterol 2013; 108: 1286-1292

[40] Lee T], Rutter MD, Blanks RG et al. Colonoscopy quality measures: experience from the NHS Bowel Cancer Screening Programme. Gut 2012; 61: 1050-1057

[41] Hilsden RJ, Rose SM, Dube C et al. Defining and applying locally relevant benchmarks for the adenoma detection rate. Am J Gastroenterol 2019; 114: 1315-1321

[42] Kastenberg D, Bertiger G, Brogadir S. Bowel preparation quality scales for colonoscopy. World J Gastroenterol 2018; 24: 2833-2843 